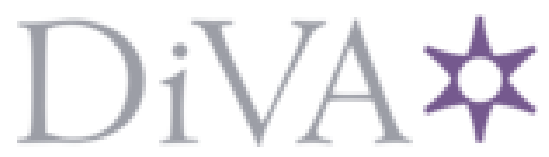

http://www.diva-portal.org

\title{
Postprint
}

This is the accepted version of a paper published in Utilities Policy. This paper has been peer-reviewed but does not include the final publisher proof-corrections or journal pagination.

Citation for the original published paper (version of record):

Picciariello, A., Vergara, C., Reneses, J., Frías, P., Söder, L. [Year unknown!]

Electricity distribution tariffs and distributed generation: quantifying cross-subsidies from consumers to prosumers.

Utilities Policy

http://dx.doi.org/doi.org/10.1016/j.jup.2015.09.007

Access to the published version may require subscription.

N.B. When citing this work, cite the original published paper.

Permanent link to this version:

http://urn.kb.se/resolve?urn=urn:nbn:se:kth:diva- 174863 


\section{Electricity distribution tariffs and distributed generation: quantifying cross-subsidies from consumers to prosumers}

Angela Picciariello*, Claudio Vergara (IIT, Comillas University, MIT), Javier Reneses (IIT, Comillas University), Pablo Frías (IIT, Comillas University), Lennart Söder (KTH)

*Angela Picciariello. School of Electrical Engineering, KTH Royal Institute of Technology

Teknikringen $33 \mathrm{KTH}, 10044$ Stockholm, Sweden

Phone: +46-769096399/Email: angela.picciariello@ee.kth.se 


\section{Abstract}

An increasing amount of distributed generation (DG) can cause an increase or a decrease on distribution network costs. Tariff design is the main tool for allocating these costs to customers who own and operate DG resources.

Currently, however, either DG units are exempt from paying distribution tariffs or they are subject to tariffs originally designed according to a traditional pricing model without DG in the grids, also known as load-based pricing. Partial recovery of the allowed distribution company revenue requirements or cross-subsidies between customers may ensue from such tariff arrangements.

In this article, pricing, as represented by a combination of net metering and pure volumetric tariffs, is applied in the context of increasing DG. The paper presents a methodology where a Reference Network Model (RNM) is used to investigate the effect of this pricing scheme on the magnitude of cross-subsidies from consumers towards the so-called prosumers for a set of twelve simulations based on real-size networks in the U.S.

For the considered scenarios, the analysis reveals substantial cross-subsidies from consumers toward prosumers. The degree of subsidy varies with the amount of DG connected to the grid and network characteristics. The rate of cross-subsidy tends to be higher for low-density grids.

This paper contributes to the net metering literature with a quantitative assessment of cross-subsidies by comparing allocated payments to different actors with the costs they impose on the system, estimated through an RNM. Moreover, the paper proposed a tariff structure based on cost causality by proposing a cost-reflective, volumetric tariff approach through which aggregate load-driven and DG-driven network costs are accordingly allocated to loads and DG units.

Key words: distribution tariffs, distributed generation, cost-allocation methodologies, cost causality, cross-subsidies.

\section{Highlights}

- Distributed generation (DG) may cause network cost increase or decrease than in a grid with no DG connected.

- The drivers behind network costs should be identified in order to design cost reflective tariffs.

- The combination of annual net metering and volumetric tariffs is investigated in detail.

- Cross-subsidies from consumers to prosumers are defined and quantitatively estimated. 


\section{INTRODUCTION}

The amount of distributed generation (DG) [1] in distribution grids has increased substantially over recent years in several countries around the world, mainly due to targeted energy policies and DG incentive mechanisms [2].

The term DG may refer to several types of technologies, ranging from traditional combustion generators (such as micro-turbines) to non-traditional ones (such as fuel cells, storage devices, and renewable sources). Photovoltaic (PV) power production and wind turbines belong to the latter category [3]. Despite not being a new concept, DG represents an innovative approach to electric power provision [3] as it affects network planning and operation. Ensuing technical changes may entail higher or lower network costs than in a passive network scenario (where no DG is connected to the grids) [4].

Two complementary mechanisms for an economically efficient DG integration are: (i) valid economic regulation of Distribution System Operators (DSOs) that takes into account potential additional costs arising from DG integration and remunerates DSOs accordingly, and (ii) sound network tariff design that efficiently allocates network costs to the users of the infrastructure. Both mechanisms are subject to review by national regulatory agencies that decide or approve the remuneration schemes for DSOs and set tariff structures or approve the tariffs set by DSOs.

The principles for proper tariff design include cost recovery, transparency, simplicity, stability, equity, and cost causality [5]. Some of them conflict with each other in the practical application.

The choice of which principles to prioritize over the others usually depends on the regulatory context and priorities [6], [7], [8]. In this paper, the priority is given to cost causality, also known as cost reflectivity.

Distribution system tariff design complexity is related to the characteristics of electrical grids. Since grid infrastructure is shared by several users, the cost for providing a service to one user depends on the services provided to other users, as well as on how the system is employed [7]. Moreover, as a result of the long life span of most of network assets, the regulator has to make decisions on behalf of network users that will impact them in the future. Furthermore, besides the difficulty of assigning cost responsibilities to each user category, there might be a need to create different incentives for different network users through tariffs (for example, to encourage load reduction or shifting during peak hours in order to optimize grid utilization).

DG integration poses additional challenges within distribution tariff design due to the difficulty of isolating DG-driven network costs and benefits and allocating them to different user categories [9]. 
Currently, such challenges generally involve either (1) exemption of DG units from paying network tariffs at all, as in most of EU countries [10], or (2) the application to DG of tariff schemes designed for load-only grids (referred to here as load-based pricing). This last case finds one of its most controversial applications in the combination of volumetric tariffs with net metering, adopted in several US States [11], [12].

Electricity tariffs are also known as DUoS (Distribution Use of System) charges, and they are paid by network users periodically; another type of network charge, known as connection charges, are paid by the network users only when they connect to the grid. Connection charges are not considered in this paper.

In general, the typical elements of an electricity tariff are [13]:

- $\quad$ A fixed charge ( $€ /$ period), meant to cover the ongoing cost of connecting the customer and metering its consumption.

- A volumetric charge ( $€ / \mathrm{kWh})$, proportionate to the energy commodity consumed by each customer, and intended to cover the variable network costs related to energy transport and distribution, and

- A capacity charge (€/( $\mathrm{kW}^{*}$ period)), also known as demand charge, collected on the contracted capacity or, more rarely, on the maximum power used during a specific time period, regardless of the consumption level. This charge is meant to cover the fixed costs of the infrastructure shared with other customers, proportionately to the capacity required by each of them.

All or some of these components can be part of an electricity tariff. Whether and how this traditional structure should be modified to better suit the new paradigm of distributed generation is still a matter of discussion. Moreover, expanded use of new pricing alternatives, such as time-of-use tariffs, might be appropriate.

Especially in the short term, electricity transmission and distribution networks are characterized by relatively high fixed costs and relatively low variable costs [14]. Therefore, energy-based (or volumetric) tariffs in distribution inherently carry a risk to the utility of not recovering the costs arising from consumption at peak times [9]. When net metering is adopted, and high DG integration is achieved, revenue risk increases due to a potential contraction in the net energy sold to the users of the network [8]. This risk is especially high when less advanced meters (providing the total net consumption over a long period of time, usually one or two months [6]) are used. In this way, the energy withdrawn by consumers, commonly during morning and evening peaks, and the energy fed into the grid during mid-day hours are likely to offset each other, thus avoiding network charges. This is an issue associated with the expanded use of rooftop solar systems [6], [15]. 
Two types of problems may arise as a consequence of tariff structures that fail to reflect network costs:

I. Utilities must absorb the unpaid network costs (a situation commonly referred to as revenue erosion), or

II. Utilities must raise tariffs to meet their revenue requirements. In practice, users without selfgeneration will have more exposure to rate increases, which can be seen as a cross-subsidy towards users with self-production (or "prosumers" that both consume and produce) [5], since one customer category ends up paying less for its use of the network than others relative to the costs they impose on the system [7].

Problem I, the revenue erosion scenario, is likely to happen when the enforced regulatory arrangements do not allow utilities to adjust tariffs because, for example, their revenues are capped; this scenario has been largely envisioned in the literature [16], [17]. However, because profit reduction seems to be more closely related to lost sales, it is more a retailer's issue rather than a network operator's issue [18].

This paper discusses the second problem. In particular, the subsidy effect of the combination of volumetric tariffs and net metering are analyzed through a computational model that is applied to twelve real-size distribution grids based on U.S. locations for different levels of PV penetration. The main contribution of the method is to enable a quantification of the cross-subsidy problem by comparing tariffs and costs caused to the system for different types of networks.

The remainder of the paper is structured as follows. Section 2 reviews the literature relevant to this paper. The proposed methodology is described in Section 3 together with a description of the study cases. Section 4 reports the results from the analyses and some insights drawn from the findings. Finally, concluding remarks and policy implications are presented in Section 5.

\section{DISTRIBUTION NETWORK CHARGES: LITERATURE REVIEW}

The literature on utility tariff design identifies several guiding principles and methodologies.

In study [5], the foundations of public utility ratemaking are laid, by identifying the main attributes of sound electricity tariffs (in terms of both theory and practice) as well as the design criteria for achieving these attributes. In [7], tariff principles are revisited and categorized into principles related to system sustainability, economic efficiency, and consumer protection. A summary of the currently adopted tariff structures in the EU countries is provided in [10]. 
In [19], a thorough overview of optimal pricing methodologies for electricity grids is presented. The overview focuses on the distribution sector; the pros and cons of traditional accounting methods and the application of long-term marginal cost (LTMC) and short-term marginal cost (STMC) methodologies are explained in detail. [19] also explores how these methodologies have recently been challenged in favor of refinements based on cost causality.

In [8], a cost-causality function is derived from a network planning function in order to identify cost drivers behind network investments for use in the tariff-setting process. However, DG is not included in the cost-allocation approaches proposed in either [19] or [8].

Few analyses of tariff-design methodologies take DG into account. In [20], the effects of a transition from an average-cost distribution tariff to a cost causation-based tariff are examined, while [21] proposes to consider the unused capacity of the existing network to reflect the cost of advancing or deferring future investments as a consequence of new DG and load connections. Both [20] and [21], however, focus on high-voltage transmission grids.

Additional analyses more specifically deal with the effects of widespread PV systems on customer charges: one study [22] investigates the impact of PV on network charges for different market structures, electricity rate structures, and PV (net metering) compensation schemes, while [23] presents the effects of different options for net metering and tariff design on cross-subsidies, cost recovery, and policy objectives.

The focus of study [22] is on retail tariffs rather than on network charges, while the analyses proposed in study [23] show that the combination of net metering and pure volumetric tariffs is most detrimental in terms of cross-subsidies when compared to alternatives (such as tariff structures including a capacity component).

Table 1 summarizes the three categories of analyses identified for the reviewed studies:

\begin{tabular}{|l|l|}
\hline \multicolumn{1}{|c|}{ Macro-category of interest } & \multicolumn{1}{|c|}{ Relevant studies } \\
\hline Foundational principles and traditional methodologies for utility pricing & [5], [7], [8], [10], [19] \\
\hline Innovative approaches to network and utility pricing & [20], [21] \\
\hline Impacts of tariff-based cross-subsidies associated with DG & [22], [23] \\
\hline
\end{tabular}

Table 1. State of art review on network tariffs and DG: relevant studies classified by categories.

In general, the literature speaks to the challenge of tariff design under a high rate of DG penetration either only theoretically and qualitatively, or without sufficient quantitative consideration of systemcost causation by customer category. This analysis investigates the connection between costs and tariffs and contributes to the literature by focusing on net metering for PV in the medium-voltage and 
low-voltage distribution systems. We further contribute to tariff design by refining application of the cost-causality principle.

Even though a variety of challenges arise from DG integration in general, utility-scale PV power plants are not considered here. The focus here is on the household level, where net metering is mostly applied and cross-subsidy issues arise.

\section{METHODS}

The objective of the methodological design here is to quantify the impact of a pure volumetric tariff combined with annual net metering on network-cost allocation in terms of cross-subsidies between customer groups. For our purposes, the two relevant customer categories are defined in terms of whether or not the customer generates power from DG. Other possible classifications, though potentially meaningful, are not considered. The impact of the "volumetric tariff plus net metering" combination is analyzed by comparison with a reference case, where cost causality is adopted as the benchmark principle for cost allocation. In other words, a cost-causality based tariff is designed and used as reference case (or cost reflective case); such cost-causality based tariff is then compared to a pure volumetric tariff combined with annual net metering in order to reveal cross-subsidies from consumers to prosumers under the latter tariff arrangement.

In order to comply with the cost-causality principle, a tariff structure should be set so that each customer's payment reflects, as much as possible, the capital and operating expenditures caused by that customer to the utility system. However, given the difficulty in tracking the costs down to every individual user of the network, customers may be divided into discrete customer categories or groups, to which the cost-causality principle and related cost-allocation rules are applied. This is usually the case in reality and, likewise in this paper in terms of DG ownership.

The methodology is composed of three steps:

1. calculation of network costs for different PV scenarios, in order to identify load-driven and $P V$-driven costs (network-cost calculation),

2. calculation of network tariffs (tariff calculation), and

3. assessment of the tariff approach in terms of cross-subsidies between customers (tariff assessment).

These three steps are explained in the following sections. 


\subsection{Network cost calculation}

Load characteristics, PV scenarios, and test networks were defined in order to estimate network costs. Costs were calculated annually, for an initial network scenario (where a base network is considered) and a future network scenario (where the network is characterized by higher load and increased PV penetration compared to the initial scenario). A more detailed explanation of the network-cost calculation is given in [24]. These costs will be referred to in the paper as $T N C_{1}$ and $T N C_{i}$ respectively (where $i$ varies with $\mathrm{PV}$ penetration scenarios).

\subsubsection{Customer characteristics}

Customers were defined at each network location by their consumption patterns and GIS coordinates. In order to determine the different demand patterns, each customer's load is characterized by the amount of contracted power as well as typical daily active and reactive power profiles (that is, 24-hour load profiles). Loads' locations were selected by using street maps that allow the identification of viable connection points through a sequential uniform integer random sampling.

\subsubsection{Definition of PV scenarios}

The PV scenarios considered here can be described in terms of $P V$ energy share and $P V$ penetration, according to the following definitions:

- $\quad P V$ penetration: the maximum instantaneous value for the ratio of aggregate PV production to aggregate total load;

- PV energy share: the ratio of total annual aggregate energy produced by PV units to the total annual aggregate energy absorbed by loads.

In this paper we use energy share as the independent variable. PV units can be connected to low voltage (LV), medium voltage (MV) and high voltage (HV) grids. Specifically, for LV and MV, it is assumed that PV units in the future network scenario are associated with existing customers, and they are matched with the customers by minimizing the net power at the time of maximum PV generation to prevent unrealistic load and generation combinations from inclusion in the simulations. As for HV, a set of pre-defined geographical locations was selected. The sizes of PV is obtained randomly from a Gaussian distribution with a different mean and standard deviation for each voltage level, and the total installed capacity to be shared among the generators is determined based on the desired energy share and typical capacity factor for the location and voltage level. 
These elements are obtained by using the daily representative PV production profiles (24-hour PV profiles) produced by the PV-Watts calculator ${ }^{1}$.

\subsubsection{Network design}

A Reference Network Model (RNM) is adopted to design distribution grids [25]. The model designs minimum-cost grids, including all the elements located between the primary substation and final customers. Minimum requirements for power quality are used as constraints of the optimization problem, and the maintenance actions required for achieving the given reliability indexes are taken into account.

The network planning process performed by the model replicates the one performed in reality by an efficient DSO. RNMs have been adopted by the Spanish Regulator to determine the remuneration for Spanish and other countries' DSOs. The RNM facilitates two types of network planning: (i) the greenfield model uses the rated power of each connection together with simultaneity factors to create the base network, and (ii) the brownfield model is used to determine the network upgrades necessary to maintain a certain quality of service under with load and generation changes.

The inputs required by the greenfield model are the location and demand of contracted HV, MV, and LV customers, as well as the location and installed capacity of DG units and transmission substations. The inputs to the brownfield model include the capacity and location of the HV/MV substations and MV/LV transformers and the existing lines layout and electrical data. The brownfield model handles load and generation hourly profiles.

The base networks for the analysis are created by applying the greenfield model to the loads described in Section 3.1.1. Initial network and future network scenarios are studied by applying greenfield and brownfield models in sequence for each PV scenario.

\subsubsection{Cost calculation}

Cost information on network investment, preventive and corrective maintenance, investments in protection devices, and energy losses are obtained as outputs of the RNM. Only network costs are relevant to tariff impacts for this analysis. In fact, energy losses are generally considered an energyonly cost, and thus not included in the network component of the tariffs nor commonly paid for by DSOs, as they concern the energy retailer [10]. Therefore, the expression total network cost in this paper refers to all the listed costs excluding energy losses.

\footnotetext{
${ }^{1}$ Available Online at: http://pvwatts.nrel.gov/
} 
Investments are assumed to be performed in the initial network and future network scenario in order to cover capital and labor costs required to build the base grid and adapt the network to the utilization rate expected in the future network scenario (-and beyond it for a pre-defined temporal horizon), respectively. No PV generators are assumed to be connected to the grid in the initial network scenario. The concept of annuity is used to calculate the total annual cost in order to concentrate investments and recurring costs in a single comparable indicator. Additionally, in order to apply a single comparable indicator across PV scenarios, the network equipment in the initial network scenario is assumed not to have reached the end of its life by the year corresponding to the future network scenario. However, in reality, DSOs' remuneration schemes may vary with equipment age depending on applicable regulations.

The total network costs in the initial network scenario $\left(T N C_{1}\right)$ are obtained as outputs of the greenfield model, where peak power values are considered for both loads and generators. A second calculation of network costs is performed by using the brownfield model. For this purpose, load and generation profiles corresponding to two critical days over the year are identified by combining the 24-hour load profile with the 24-hour PV profile, with and without PV production. Peak-load and peak-generation instances are in this way represented.

The PV penetration corresponding to each scenario is assumed to be achieved in the grid at any undefined point of time between the initial network scenario and the future network scenario. The brownfield model assumes that future load and PV scenarios are known in advance and that necessary grid investments ( $T N C_{i}$ for each PV scenario $i$ ) will be made to cope with them in the future. Fig. 1 exemplifies the main steps of the cost calculations done through the RNMs.

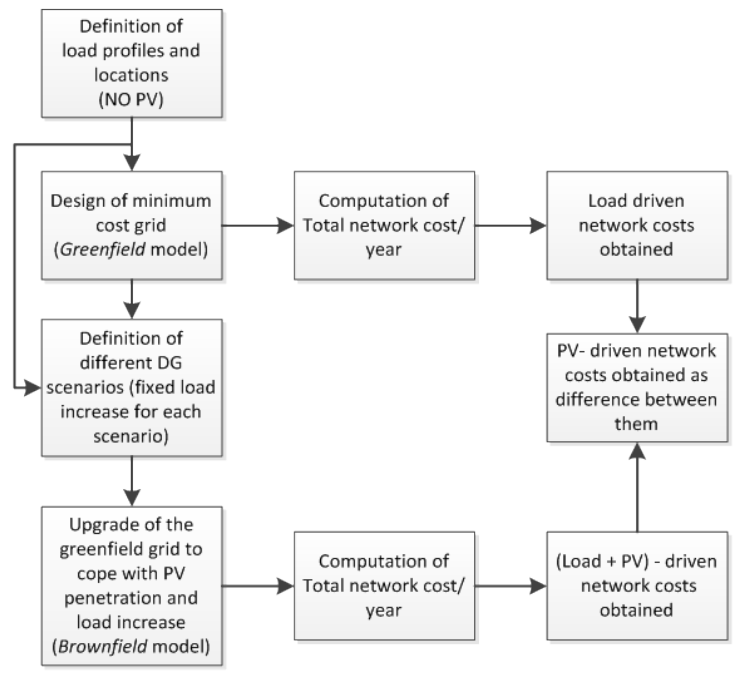

Fig. 1. Network costs calculation for the greenfield and brownfield models. 
In general, three types of network users can be identified, depending on their net consumption or production of active power as represented by $P$ :

- Consumers, if $P$ is always positive or equal to zero,

- Producers, if $P$ is always negative or equal to zero, and

- Prosumers, if $P$ is sometimes positive and sometimes negative.

In this analysis, no producers are considered, since we assumed that PV systems are always connected at buses where loads are already connected (household rooftop PV units) at the LV and MV level.

For the purposes of calculating network tariffs and assessing their impact, Total Network Costsi for each scenario were split into: Load-driven costs (Load Costs ${ }_{i}$ ) and PV-driven costs (PV Costs ${ }_{i}$ ), as in (1) and (2):

$$
\begin{aligned}
& {\text { Load } \text { Costs }_{i}}^{=} \text {Total Network Costs } \\
& \text { PV Costs } \\
& \text { Cotal Network Costs }_{i}-\text { Total Network Costs }
\end{aligned}
$$

where $i=1: n$ represents the different scenarios of PV penetration. Both (1) and (2) rely on an assumption of a fixed-load increase between the initial and future network scenario for each scenario $i$. This implies that PV-driven costs in each scenario are represented by the difference between total annual cost for that scenario and the annual network costs in the initial network scenario; the latter are, in fact, completely attributable to loads.

Since consumption is present both at consumer and prosumer buses, it is necessary to separate these contributions in terms of absorbed energy and costs imposed on the system. Therefore, loads are further split into the two categories of consumers (i.e. loads located at consumer buses) and prosumer loads (i.e. the load components of prosumer buses).

The share of costs attributable to consumer buses (Consumer Costs $s_{i}$ ) is calculated by multiplying total network costs by the ratio between the annual aggregate energy absorbed by consumers (Consumer Energy ${ }_{i}$ ) and the annual aggregate net energy for all customers (Total Net Energy $y_{i}$ ). The share of costs attributable to prosumer buses (Prosumer Costs $s_{i}$ ) is obtained by summing up PVdriven costs previously calculated and the share of load-driven costs that can be attributed to the load components of prosumer buses (Prosumer_Load Costs ${ }_{i}$ ):

$$
\text { Consumer } \text { Costs }_{i}=\text { Total Network Costs } s_{i} \cdot \frac{\text { Consumer Energy }}{i}
$$




$$
\begin{aligned}
& \text { Prosumer_Load Costs }{ }_{i}=\text { Load Costs }_{i}-\text { Consumer Costs }_{i} \\
& \text { Prosumer Costs }_{i}=\text { Prosumer_Load Costs }_{i}+\text { PV Costs } \\
& \text { Pro }
\end{aligned}
$$

Any negative net annual energy measured at one bus is set equal to 0 under the assumption that no network charge is imposed on injected energy.

Fig. 2 illustrates the two classifications of network costs based on technical nature and the driving agent of the costs; the proportions of cost shares in the figure are arbitrary.

The cost allocation was executed solely based on an energy indicator. This choice is consistent with the application of a pure volumetric charge, which suggests that "energy-use" might be the only available input when setting the tariffs.

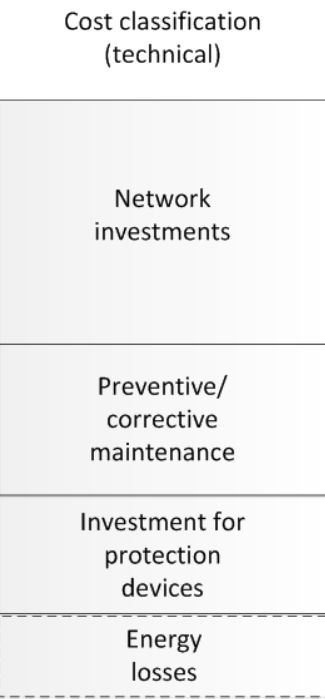

Customer classification
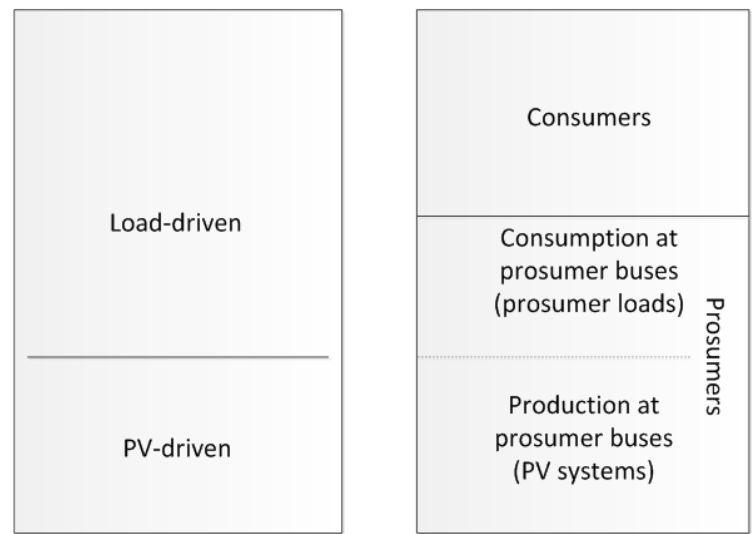

Fig. 2. Classification of network costs into categories.

\subsection{Tariff calculation}

Meters are a determining element for the tariff structure as metering capabilities affect the information available with regard to user consumption profiles.

Two metering approaches are considered: (i) net metering, which gives the annual netting of consumed and produced energy, and (ii) two separate meters, which measure produced and consumed energy separately. The latter is adopted as the reference, cost-reflective case. The two meters are assumed to measure the total gross energy absorbed by each load and the total gross energy produced by the correspondent PV power plant; that is, the share of the energy potentially 
produced by the PV system and internally consumed by the load is not deducted from the measurements.

The annual Unit Volumetric Tariffi is calculated for the net metering case according to (6): the Total Network Costsi obtained from running both the greenfield and brownfield models and including capital and operational costs, divided by the Total Net Energy ${ }_{i}$. The Unit Volumetric Tariffi is then applied for charging both consumers and prosumers.

$$
\text { Unit Volumetric Tarif } f_{i}=\frac{\text { Total Network } \operatorname{Costs}_{i}}{\text { Total Net Energy }}
$$

\subsection{Tariff assessment}

Assessing the validity of network tariffs is complex, since different evaluation criteria might be chosen and different weights assigned to each of them based on regulatory priorities [26]. Moreover, the criteria often conflict [8]. This analysis adopts cost reflectivity as main criterion for assessing the validity of distribution-network tariffs.

In order to carry out an analysis of cross-subsidies, it is necessary to first define cross-subsidies and then to analyze when and why they are likely to appear.

It is difficult to define cross-subsidies because it is difficult to measure them, and vice versa [27]. Two potential sources of cross-subsidy are identified in [27]: the existence of costs that are common to more than one output, and the existence of a monopoly with its inherent potential for exercise of market power by the monopolist, if not adequately regulated. Both factors characterize electricity distribution networks. The key to establishing the presence of cross-subsidy is the application of unequivocal assessment criteria. Two approaches are recognized in [27]: one is to use benchmarks generated through a cost-allocation study and the other is to consider optimal pricing rules. In this paper, we use a cost-allocation benchmark considering the incremental costs (IC) required for accommodating an increasingly higher amount of DG units. In this case, the analysts [27] suggest that the output $j$ is the recipient of cross-subsidy if $p j<(I C) j$, with $p$ representing the aggregate tariff paid by DG units.

In order to define a rate of cross-subsidization between consumers and prosumers, their respective annual payments must be calculated. These payments are the product of the Unit Volumetric Tariff $i$ times the aggregate net energy absorbed by consumers over one year (Consumer Energy $y_{i}$ ) and the one absorbed by prosumer buses (Prosumer Energy $y_{i}$ ), respectively, as in (7) and (8). A Consumer Payment $_{i}$ and a Prosumer Payment ${ }_{i}$ are, thus, obtained: 
As the number of prosumer buses increases with the number of PV units connected to the grid and the number of consumer buses decreases accordingly, Consumer Payment $i_{i}$ and Prosumer Payment $_{i}$ need to be normalized. This is done by dividing them by consumer and prosumer cost shares, respectively, as in (9) and (10):

$$
\begin{aligned}
& \text { Consumer Payment_n } n_{i}=\frac{\text { Consumer Payment }}{\text { Consumer Costs }_{i}} \\
& \text { Prosumer Payment_n } n_{i}=\frac{\text { Prosumer Payment }}{\text { Prosumer-Load Costs }_{i}}
\end{aligned}
$$

Finally, the rate of Cross - Subsidization $i$ is calculated in (11) as the difference between the normalized annual payments of consumers and prosumers. Cross-subsidies are, in this way, obtained by summing up the consumer contribution (the ratio between the consumer payment and the consumer-driven costs), and the prosumers contribution (the ratio between the prosumer payment and the prosumer-driven costs). The minus sign in (11) is used to consistently sum up the two contributions. In fact, the first term is positive and the second term is negative if loads are crosssubsidizing PV, and vice versa. The rate of Cross - Subsidization ${ }_{i}$ is expressed in p.u.

$$
\text { Cross }- \text { Subsidization }_{i}=\text { Consumer Payment_n } n_{i}-\text { Prosumer Payment_ } n_{i} \quad \text { [p.u.] }
$$

\subsection{Reference case: cost-reflective tariffs}

The use of two separate meters for consumed and produced energy allows separate charging of consumption and production; this is particularly relevant with regard to prosumers.

For our reference case, two different tariffs are calculated under the assumption that both producers and consumers are subject to the application of distribution network charges designed to be reflective of load-driven and PV-driven costs as calculated in section 3.1.4. Cost reflectivity is achieved by separately allocating the share of total network costs driven by PV systems production and the share of total network costs driven by load consumption to production and consumption units respectively; both the calculation of such cost shares and their allocation to the two customer categories through tariffs are done according to a volumetric principle. This means that prosumers are charged both as consumers and producers by means of two different charges.

Therefore, a Load Vol Tariff ${ }_{\mathrm{i}}$ is calculated as load-driven cost divided by aggregate energy absorbed by loads over one year (Load Energy L $_{i}$. A PV Vol Tariff $f_{i}$ is calculated by dividing the PV-driven 
cost by the aggregate energy injected by PV units (PV Energy $\left.y_{i}\right)$ over one year. The two tariffs are calculated according to (12) and (13):

$$
\begin{aligned}
& \text { Load Vol Tarif }_{i}=\frac{\text { Load Cost }_{i}}{\text { Load Energy }_{i}} \\
& \text { PV Vol Tariff } f_{i}=\frac{\text { PV Total Costs }}{\text { Tot }_{i}}
\end{aligned}
$$

In line with the net metering case, annual payments by consumers and prosumers are calculated in the case of two different meters, according to (14) and (15):

$$
\text { Consumer Payment_ } r_{i}=\text { Load Vol Tarif } f_{i} \cdot \text { Consumer Energy } y_{i}
$$

Prosumer Payment_ $r_{i}=$

Load Vol Tariff $f_{i} \cdot$ Prosumer Energy $_{i}+$ PV Vol Tariff ${ }_{i} \cdot$ PV Energy $y_{i}$

The payments are normalized by the corresponding shares of network costs driven by consumers and prosumers, as in (16) and (17):

$$
\begin{aligned}
& \text { Consumer Payment_r } r_{-} n_{i}=\frac{\text { Consumer Payment_} r_{i}}{\text { Consumer Costs }_{i}} \\
& \text { Prosumer Payment_r } n_{i}=\frac{\text { Prosumer Payment_r } r_{i}}{\text { Prosumer Total Cost } s_{i}}
\end{aligned}
$$

Finally, the rate of cross-subsidization for the reference case is calculated in Eq. (18):

Cross Subsidization_ $r_{i}=$ Consumer Payment_ $r_{-} n_{i}-$ Prosumer Payment_ $r_{-} n_{i} \quad$ [p.u.] (18)

Given that the tariffs in the reference case are considered inherently cost reflective, the rate of crosssubsidization is equal to 0 in the reference case.

\subsection{Description of study cases}

The described methodology is applied to several study cases. The different cases vary in terms of the following parameters:

1. Network types: 12 realistically sized networks from 6 US states are used.

2. $\quad P V$ penetration and energy share: the simulations for each network are performed for different PV scenarios based on PV penetration or energy share, according to the definitions given in section 3.1.2.

3. Dominant load profile: predominantly residential load profiles are adopted: in particular, they present $80 \%$ residential, $15 \%$ commercial and 5\% industrial component for each voltage level. 
Residential and commercial load profiles are obtained by using the simulation software Energy Plus and data from the TMY3 database for the 12 locations [28]. Nearly constant consumption with $10 \%$ hourly variability is assumed for the industrial load profiles. All PV systems generate at unitary power factor and a $2 \%$ annual load increase is assumed [24]. The selected network locations are listed in Table 2. The networks are not directly associated with the corresponding municipalities; they were simply designed by using GIS coordinates and load information corresponding to each city.

\begin{tabular}{|l|l|l|}
\hline State & Low density network & High density network \\
\hline California & Lancaster & Los Angeles \\
\hline Colorado & Eaton & Boulder \\
\hline Connecticut & Torrington & Hartford \\
\hline Iowa & Altoona & Des Moines \\
\hline Texas & San Marcos & Austin \\
\hline Washington & Covington & Seattle \\
\hline
\end{tabular}

Table 2. Network locations selected for the case studies.

\begin{tabular}{|c|c|c|c|c|c|c|}
\hline PV Scenarios & \multirow{9}{*}{ 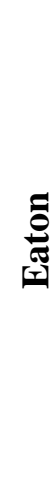 } & Penetration & Energy share & \multirow{9}{*}{ 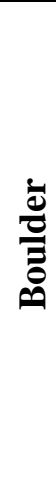 } & Penetration & Energy share \\
\hline 1 & & 0.0023 & 0.0006 & & 0.0012 & 0.0003 \\
\hline 2 & & 0.0931 & 0.0249 & & 0.1681 & 0.0453 \\
\hline 3 & & 0.2562 & 0.0728 & & 0.3667 & 0.0993 \\
\hline 4 & & 0.3434 & 0.0961 & & 0.5415 & 0.1475 \\
\hline 5 & & 0.5041 & 0.1435 & & 0.7081 & 0.1927 \\
\hline 6 & & 0.6015 & 0.1677 & & 0.9189 & 0.2492 \\
\hline 7 & & 0.6450 & 0.1795 & & 1.0908 & 0.2962 \\
\hline 8 & & 0.9089 & 0.2550 & & 1.2572 & 0.3409 \\
\hline
\end{tabular}

Table 3. PV penetration and PV energy share scenarios for Eaton and Boulder networks.

Some explicative results are proposed and discussed in the following section. Cross-subsidization results follow similar trends with increasing PV penetration for all of the grids considered. The networks from Eaton and Boulder (Colorado) are highlighted here as representative of a low-density and a high-density network, respectively. The PV scenarios are summarized in Table 3, in terms of penetration and energy share. 


\section{RESULTS AND DISCUSSION}

\subsubsection{Network cost}
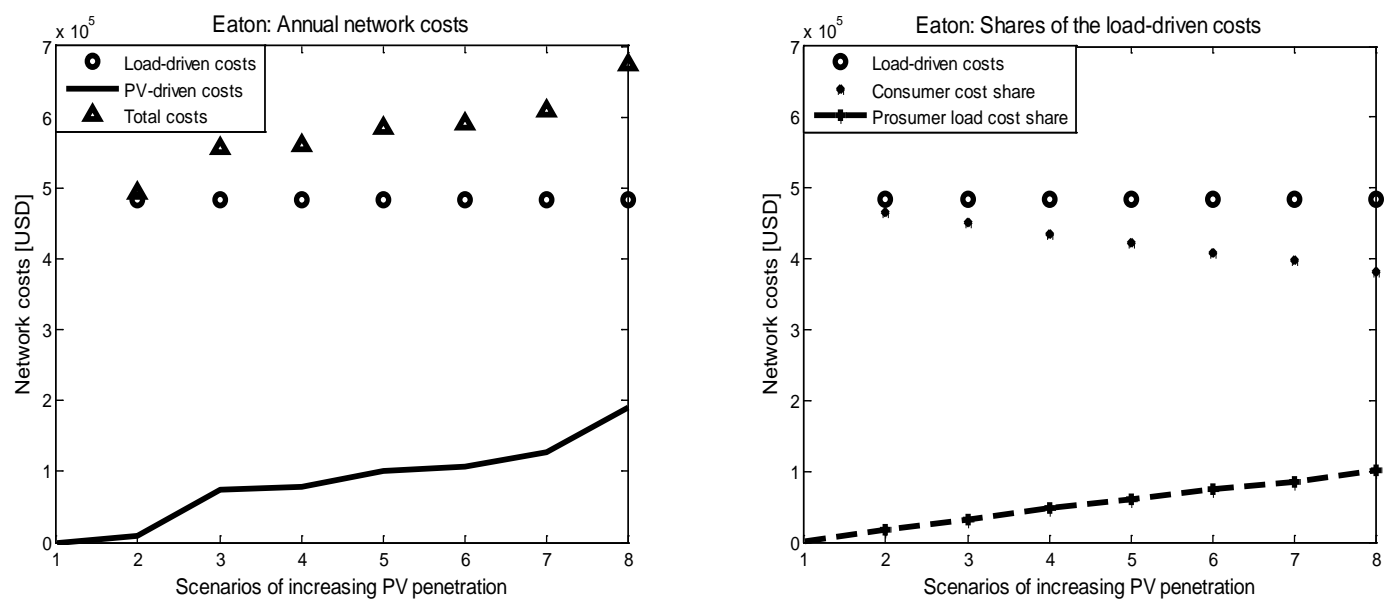

Fig. 3. Annual network costs for scenarios of increasing PV penetration (Eaton network).
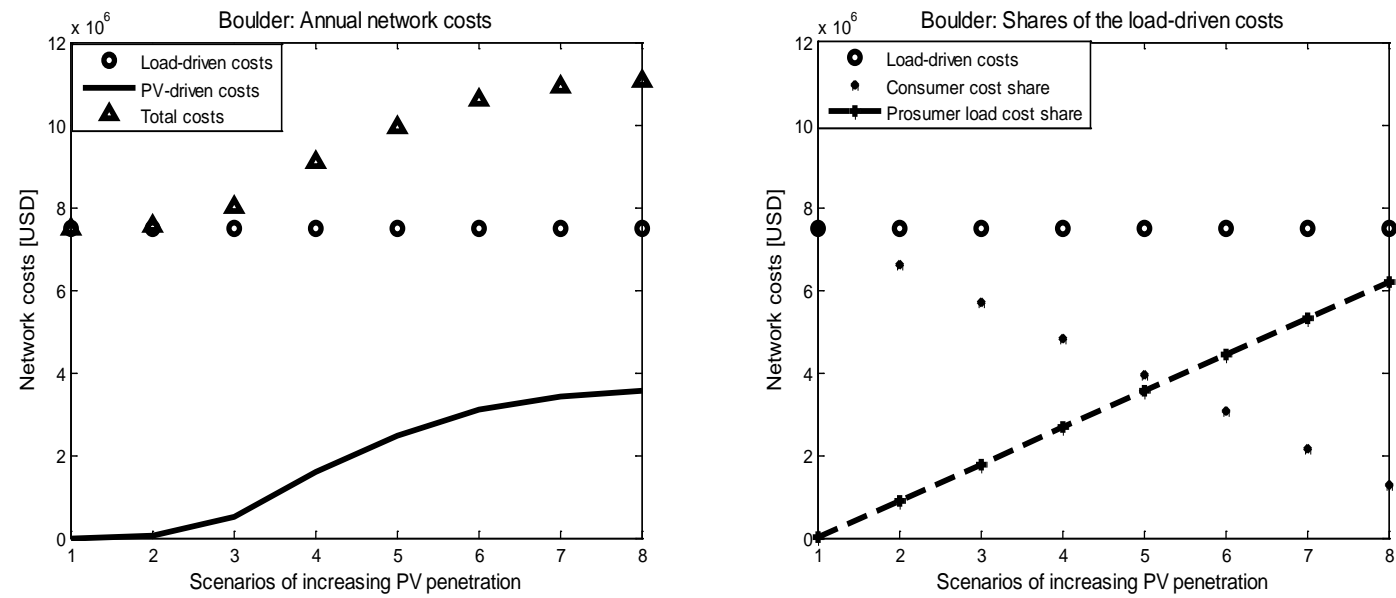

Fig 4. Annual network costs for scenarios of increasing PV penetration (Boulder network).

The annual total network costs are shown on the left-hand side of Fig. 3 and Fig. 4 for the two networks; the shares of the total costs associated to loads and PV units are also represented.

As expected, network costs tend to increase with PV penetration due to the grid investments needed to accommodate the new generation units. 
On the right-hand side of the two figures, the load-driven costs are further split into the ones associated to load buses and to prosumer buses.

The graphs are formatted for purposes of visualization but are not intended to represent continuous trends. From Fig. 3 and Fig. 4, it can be seen that the load-driven share of the total costs does not vary among the different PV scenarios. Therefore, the total cost curve has the same shape as the PVdriven cost curve.

The share of costs associated to consumer buses decreases and the one attributable to prosumer buses increases with PV penetration. This result is expected as the number of consumer buses becoming prosumer buses increases with PV penetration.

\subsubsection{Net metering and volumetric tariff}
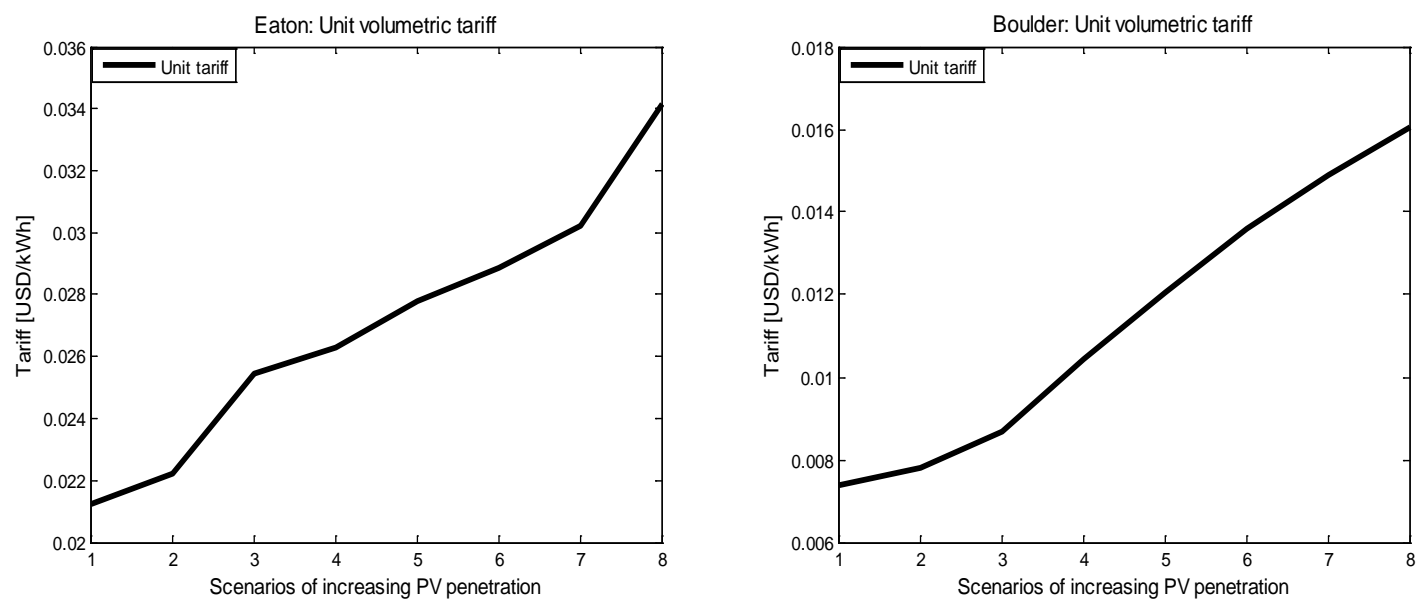

Fig. 5. Unit volumetric tariff for scenarios of increasing PV penetration.

Fig. 5 shows the unit volumetric tariff for different PV scenarios. For both networks, the tariff rate increases due to increased total network costs as well as to decreased aggregate energy sold.

However, the tariff rate alone is not sufficient for understanding the relationship between network charges and the share of costs driven by the two types of customers. Normalized annual payments by loads and prosumers are shown in Fig. 6. 

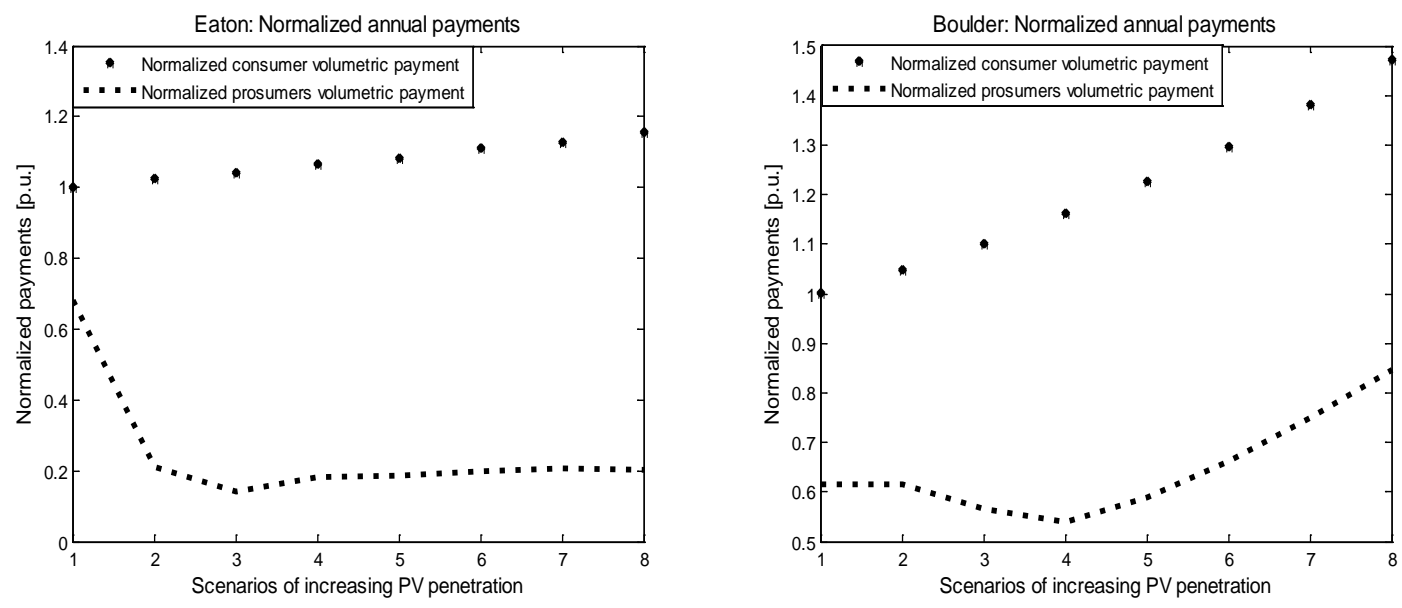

Fig. 6. Normalized annual payments by consumers and prosumers for scenarios of increasing PV penetration.

Fig. 6 reveals that the payments by consumers normalized by consumer-driven costs increase with PV penetration for both networks: normalized payments equal to 1 would mean that the corresponding customer group is paying only as much as the costs it imposed on the system. The graphs show that the payments by prosumers decrease in the Eaton network and increase (but at a lower rate than consumer ones) in the Boulder network. It is clear from the Eaton example that the steepest decrease in prosumer payments occurs between scenario 1 and scenario 3. This finding can be explained by the presence of large economies of scale for electricity networks, such that it might be more expensive to upgrade a grid for accommodating lower amounts than higher amounts of DG. This result, however, may be case-dependent and not generalizable.

The calculation of the rate of cross-subsidization, presented in Fig. 7, confirms the previous results: the ideal rate, under a perfect cost causality-based allocation methodology, would be 0 in each scenario, whereas the real one increases between scenarios 1 and 8, from 0.32 up to 0.95 for the less dense Eaton network, and from 0.39 to 0.63 for the more dense Boulder network. 

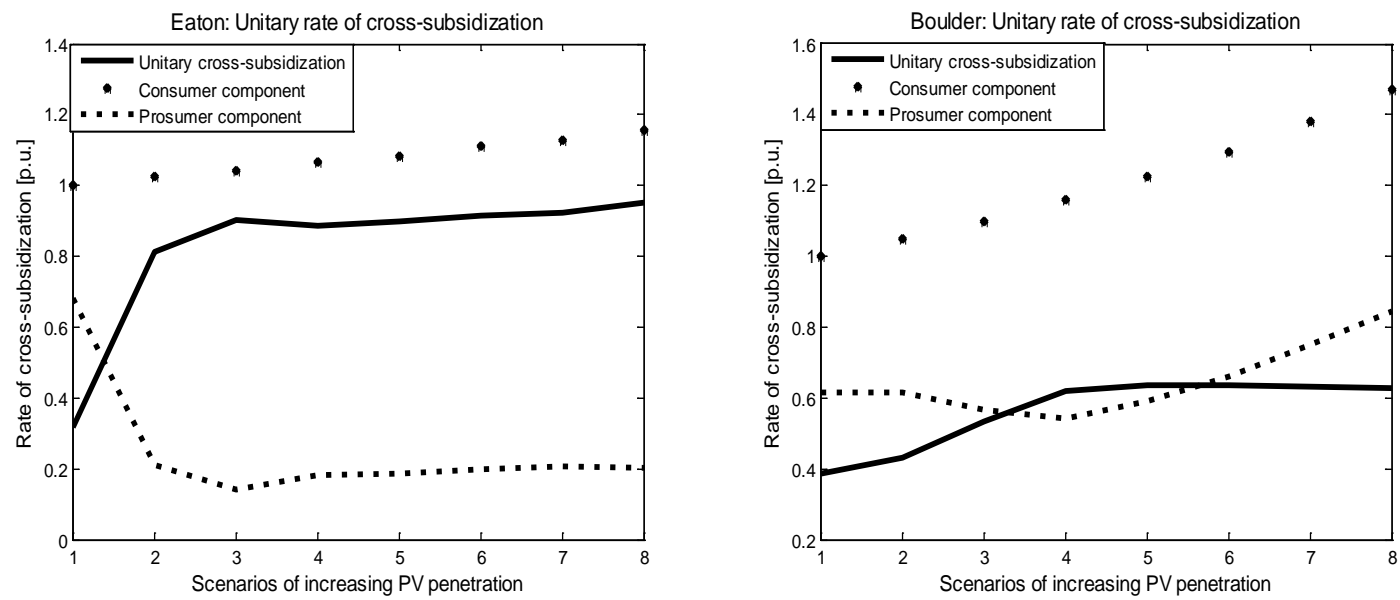

Fig. 7. Rate of cross-subsidization for scenarios of increasing PV penetration.

In both cases shown in Fig. 7, the increase in the rate of cross-subsidization is quite dramatic across the first scenarios, while growing at a slower pace afterwards and decreasing slightly for the last two PV scenarios.

Results for the rate of cross-subsidization for the 12 networks are summarized in Table 4.

\begin{tabular}{|c|c|c|c|c|c|c|c|c|c|}
\hline \multirow{13}{*}{ 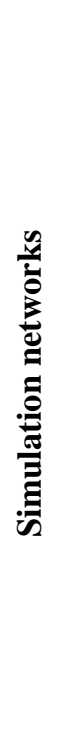 } & & PV1 & PV2 & PV3 & PV4 & PV5 & PV6 & PV7 & PV8 \\
\hline & Lancaster & 0.8651 & 0.8843 & 0.9391 & 0.9785 & 1.0107 & 1.0445 & - & - \\
\hline & Los Angeles & 0.3327 & 0.4211 & 0.5813 & 0.6426 & 0.6288 & 0.6023 & - & - \\
\hline & Eaton & 0.3187 & 0.8131 & 0.9010 & 0.8854 & 0.8977 & 0.9163 & 0.9216 & 0.9506 \\
\hline & Boulder & 0.3859 & 0.4330 & 0.5335 & 0.6206 & 0.6351 & 0.6348 & 0.6323 & 0.6271 \\
\hline & Torrington & 0.5560 & 0.8978 & 0.9058 & 0.9194 & 0.9144 & 0.9193 & 0.9191 & 0.9405 \\
\hline & Hartford & 0.2571 & 0.4239 & 0.5118 & 0.5723 & 0.5478 & 0.4932 & 0.4664 & 0.4473 \\
\hline & Altoona & 0.7403 & 0.9549 & 0.9629 & 0.9833 & 0.9894 & 1.0207 & - & - \\
\hline & Des Moines & 0.3085 & 0.5124 & 0.5360 & 0.6052 & 0.5906 & 0.5663 & - & - \\
\hline & San Marcos & 0.7804 & 0.9390 & 0.9410 & 0.9323 & 0.9481 & 0.9698 & 1.0006 & 1.0229 \\
\hline & Austin & 0.2910 & 0.6200 & 0.6568 & 0.7297 & 0.7493 & 0.7349 & 0.7320 & 0.7214 \\
\hline & Covington & 0.6371 & 0.9138 & 0.9173 & 0.9529 & - & - & - & - \\
\hline & Seattle & 0.2177 & 0.4288 & 0.4915 & 0.5724 & - & - & - & - \\
\hline
\end{tabular}

Table 4. Rate of cross-subsidization rate for the different networks and PV scenarios.

The meaning of the cross-subsidization index can be explained as follows: the two contributions from normalized payments by prosumers and loads are summed up so to obtain the total cross-subsidization; in other 
words, the total is the sum of what one customer category pays in excess of cost caused and what the other category avoids paying despite costs caused.

Significant differences can be noticed among the different networks and scenarios with respect to crosssubsidization. These differences can be explained by differences in grid configurations, geographic and weather conditions, and customer profiles (especially in terms of the timing of load and PV generation). In particular, cross-subsidies for high-density networks are about half those corresponding to low-density grids. This result can be explained by lower integration costs for high-density (urban) grids than for low-density (rural) grids.

Despite the potential for DG potentially to have a twofold effect on grid costs, the obtained results show only a negative impact. This finding may depend on the specific grids and DG scenarios chosen and the exclusion of network losses from the analysis. Moreover, given PV production variability by time of day and season of the year, different results might be expected for different grid locations.

\subsubsection{Reference case}

As Fig. 8 shows for the reference case that, for both networks, PV volumetric payments coincide with the PV-driven share of total costs. The total payment by consumers decreases with the successive PV scenarios, while the prosumer load payment increases.
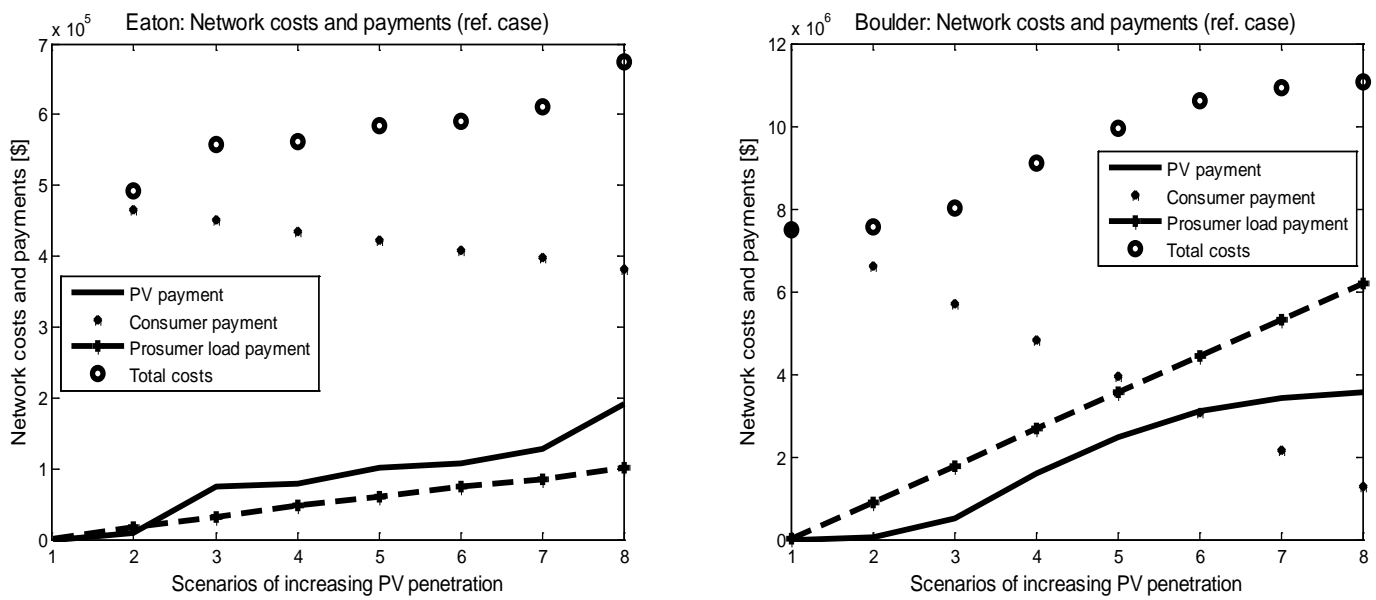

Fig. 8. Annual network costs and annual payments by consumers and prosumers for scenarios of increasing PV penetration, reference case.

The tariffs for loads and PV units are shown in Fig. 9: while the load tariff is constant over the PV scenarios, this way reflecting the load-driven cost trend, the one for PV increases. 

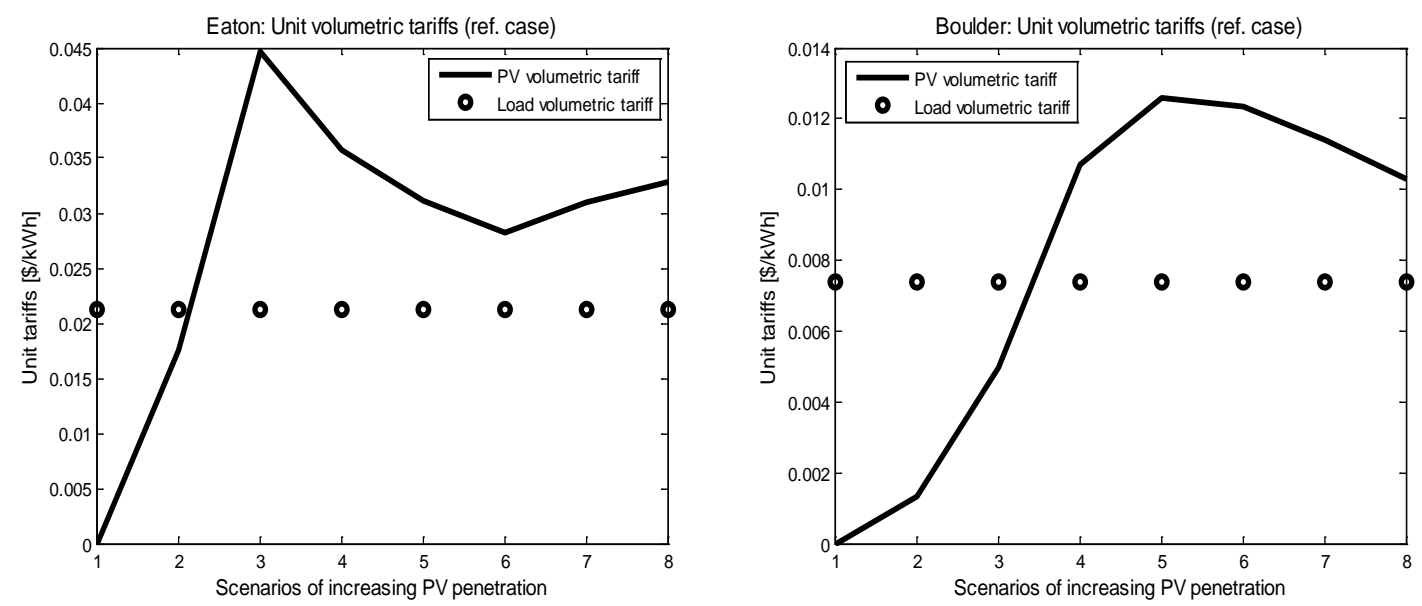

Fig. 9. Unit volumetric tariffs for loads and PV for scenarios of increasing PV penetration, reference case.

\section{CONCLUSIONS AND POLICY IMPLICATIONS}

This paper analyzed distribution tariff design in the context of increasing amounts of distributed generation (DG) in distribution grids. The combination of net metering and pure volumetric tariffs was analyzed, and tariff impacts were assessed relative to the cost-causality principle.

The methodology was composed of three steps: the calculation of network costs for different PV scenarios through Reference Network Models in order to differentiate between load-driven and PVdriven costs; the design of network tariffs based on the network-cost calculation; and the assessment of the tariffs in terms of potential cross-subsidies between customer groups. A reference case was built in order to compare results obtained under different scenarios with results under an ideal, costreflective tariff. Cost-reflective tariffs were achieved through volumetric charges separately applied to the energy consumed and produced at each customer point.

Results show that cross-subsidies arise when net metering combined with pure volumetric tariffs is applied, as this approach to pricing electricity is not adequate to properly reflect of load-driven and PV-driven costs. Based on various scenarios, the rate of cross-subsidization varies with the amount of DG connected to the grid and network characteristics and is higher in low-density networks.

New cost-allocation and tariff-design methodologies are needed in order for electricity prices to better reflect costs based on grid usage. In order for tariffs to be practical, it may be necessary to refine customer groups according to key cost drivers. 
Future work should investigate the impact of time horizons other than one year for calculating net energy usage within the meters. Moreover, the possibility of implementing negative charges (credits) for prosumers when their total aggregate energy is negative (instead of the zero-tariff value utilized here) is worth exploring. Similarly, in the separate meters case, the consumed and injected energy should be calculated after deducting the energy internally consumed. Furthermore, the aggregate analyses presented here do not capture differences among prosumers: although they both fall under the same "charging” category, some might be mainly consumers, with only low and sporadic production, while others might be mainly producers.

Not including network losses in the distribution tariffs represents a realistic assumption as losses are currently treated as a retailer cost. However, as DG penetration rises, it may be necessary to incorporate these costs in distribution tariffs. Moreover, network losses might have an impact on investment costs and DG might have an impact on network-loss levels; the combined effect of these two factors was neglected in this analysis.

Establishing a totally cost reflective tariff is very challenging in practice. Cross-subsidies between consumers and prosumers, and within each respective group, still occur in our reference case depending, for example, on the location and timing of the connection. In other words, some cost averaging is still used. In order for tariffs to become more cost reflective, and calculable ex-ante, network cost drivers and allocation rules must be clearly identified. Tariff regulators, and society as a whole, must set acceptable standards for cost reflectivity. Such standards have long been used for differentiating customer categories by usage volume, income levels, or other criteria and are often subject to broad policy considerations. However, regardless of policy objectives, a high level of transparency should be ensured in order for cross-subsidies to be understood and reduced as appropriate.

\section{ACKNOWLEDGMENTS}

Angela Picciariello has been awarded a SETS Erasmus Mundus PhD Fellowship (Partner universities: Comillas University, KTH, TU Delft). The authors would like to express their gratitude towards all partner institutions within the program as well as the European Commission for their support.

\section{REFERENCES}

[1] T. Ackermann, G. Andersson and L. Söder, “Distributed generation: a definition,” Electric 
Power Systems Research, vol. 57, pp. 195-204, April 2001.

[2] J. Peças Lopes, N. Hatziargyriou, J. Mutale, P. Djapic and N. Jenkins, "Integrating distributed generation into electric power systems: A review of drivers, challenges and opportunities," Electric Power Systems Research, vol. 77, no. 9, pp. 1189-1203, July 2007.

[3] W. El-Khattam and M. Salama, "Distributed generation technologies, definitions and benefits," Electric Power Systems Research, vol. 71, pp. 119-128, October 2004.

[4] R. Cossent, L. Olmos, T. Gómez, C. Mateo and P. Frias, "Distribution network costs under different penetration levels of distributed generation,” European Transactions on Electrical Power, vol. 21, no. 6, pp. 1869-1888, September 2011.

[5] J. Bonbright, "Principles of public utility rates”, Arlington, Virginia, 1961.

[6] THINK project. Final report, "From Distribution Networks to Smart Distribution Systems: Rethinking the Regulation of European Electricity DSOs,” June 2013.

[7] V. Sakhrani and J. E. Parson, "Electricity network tariff architectures. A comparison of four OECD countries," Centre for Energy and Environmental Policy Research (CEEPR), 2010.

[8] M. P. Rodríguez Ortega, J. I. Pérez-Arriaga, J. Rivier Abbad and J. Peco Gónzalez, "Distribution network tariffs: A closed question?,” Energy Policy, pp. 1712-1725, May 2008.

[9] A. Picciariello, J. Reneses, P. Frias and L. Söder, "Distributed generation and distribution pricing: why do we need new tariff design methodologies?,” Electric Power Systems Research, 119, pp. 370-376, February 2015.

[10] EURELECTRIC, “Network tariff structure for a smart energy system,” May 2013.

[11] Sara Baldwin, Auck Justin, Barnes Thad, Culley Rusty, Haynes Laurel, Passera Joseph Wiedman, Rosalind Jackson and Rick Gilliam, "Freeing the Grid: Best Practices in State Net Metering Policies and Interconnection Procedures," Network for New Energy Choices, New York, NY, 2014.

[12] Sioshansi Editor, "Distributed Generation and Its Implication for the Utility Industry, Energy Informer,” 2014. [Online]. Available: http://www.eenergyinformer.com/. [Accessed 03-062015].

[13] Firestone, Ryan; Magnus Maribu, Karl; \& Marnay, Chris. "The Value of Distributed Generation under Different Tariff Structures.” Lawrence Berkeley National Laboratory. 2006. from: https://escholarship.org/uc/item/59x81424

[14] Econ Pöyri AS, “Optimal network tariffs and allocation of costs. report 2008-129,” 2008. [Online]. Available: http://www.nve.no/Global/Kraftmarked/Tariffer/Optimal\%20network\%20tariffs\%20and\%20all ocation\%20of\%20costs.pdf?epslanguage=en.

[15] Interstate Renewable Energy Council (IREC), “"Connecting to the grid" Project State and Utility Net Metering Rules for Distributed Generation,” 2010.

[16] Graham, Shannon, et al. "Future of Grid-Tied PV Business Models: What Will Happen When PV Penetration on the Distribution Grid is Significant?," National Renewable Energy 
Laboratory, Conference paper, SOLAR, American Solar Energy Society (ASES). 2008.

[17] A. Brown and L. Lund, "Distributed Generation: How green? How efficient? How wellpriced?,” The Electricity Journal, vol. 26, no. 3, pp. 28-34, April 2013.

[18] K. Costello and L. Hemphill, "Electric utilities' 'death spiral': hyperbole or reality?,” The Electricity Journal, vol. 27, no. 10, pp. 7-26, December 2014.

[19] J. Reneses and M. P. Rodriguez, "Distribution pricing: theoretical principles and practical approaches,” IET Generation, Transmission \& Distribution, vol. 8, no. 10, p. 1645-1655, October 2014.

[20] P. M. Sotkiewicz and M. Vignolo, "Towards a cost causation-based tariff for distribution networks with DG,” IEEE Transaction on Power Systems, vol. 22, no. 3, pp. 1051-1060, August 2007.

[21] F. Li and D. L. Tolley, “Long-run incremental cost pricing based on unused capacity,” IEEE Transaction on Power Systems, vol. 22, no. 4, pp. 1683-1689, November 2007.

[22] N. Darghouth, G. Barbose, R. H. Wiser. "Customer-economics of residential photovoltaic systems (Part 1): The impact of high renewable energy penetrations on electricity bill savings with net metering." Energy Policy, vol. 67, pp. 290-300, April 2014.

[23] C. Eid, J. Reneses, P. Frías and R. Hakvoort, "The economic effect of electricity net-metering with solar PV: Consequences for network cost recovery, cross subsidies and policy objectives," Energy Policy, vol. 75, pp. 244-254, December 2014.

[24] C. Vergara, I. Pérez Arriaga, C. Mateo and P. Frías, "Estimate the aggregate impact of distributed photovoltaic generation over distribution networks,” Working paper IIT-14-034A. Instituto de Investigación Tecnológica Universidad Pontificia Comillas, 2014.

[25] C. G. T. Mateo, S. A., J. González and A. Martínez, "A Reference Network Model for largescale distribution planning with automatic street map generation," IEEE Transaction on Power Systems, vol. 26, no. 1, pp. 190-197, February 2011.

[26] F. Li and D. Tolley, "Framework for Assessing the Economic Efficiencies of Long-Run Network Pricing Models,” IEEE Transaction on Power Systems, vol. 24, no. 4, pp. 1641-1648, November 2009.

[27] D. Heald, "Contrasting approaches to the "problem" of cross subsidy,” Management Accounting Research, vol. 7, pp. 53-72, March 1996.

[28] “U. S. N. R. E. Laboratory, “Typical meteorological year 2006.,” [Online]. Available at: http://rredc.nrel.gov/solar/old_data/nsrdb/1991-2005/tmy3/ 